\title{
FORMAÇÃO INICIAL DE TRABALHADORES: POLÍTICAS, DESAFIOS E CONQUISTAS NA EDUCAÇÃO PROFISSIONAL
}

\author{
Aparecida de Fátima Soane LOMÔNACO ${ }^{1}$ \\ Eneida de Mattos FALEIROS ${ }^{2}$
}

\begin{abstract}
RESUMO: Este estudo tem como objetivo discutir a formação inicial junto à proposta de Habilitação do Agente Comunitário de Saúde (ACS). Trata-se de uma pesquisa de natureza qualitativa, com coleta aleatória dos dados discursivos de 100 profissionais, que constituem a base empírica da pesquisa, de janeiro a maio de 2008. As perspectivas delineadas para a Educação Profissional Brasileira no setor saúde, com destaque para a inclusão social dos trabalhadores pela elevação de sua escolaridade, impõem políticas públicas educativas específicas. A proposta para profissionalização do pessoal de nível médio em atuação no setor da saúde é de uma política de formação a partir de itinerários formativos. Em 2004, o referencial curricular para o Curso Técnico de ACS propõe um curso modular com carga horária de 1200 horas, com conteúdo teórico e prático. Em 2007, a Escola Técnica de Saúde da UFU, em parceria com a Escola de Saúde Pública de MG e GRS de Uberlândia e Ituiutaba, Minas Gerais, Brasil, desenvolve o Módulo I do Curso de formação inicial, carga horária de 400 horas, envolvendo 857 alunos e 200 professores. Conclui-se haver melhoria satisfatória na prestação de serviços pelo profissional melhor capacitado e pela necessidade de um amplo debate sobre a continuidade das políticas públicas para a Educação Profissional.
\end{abstract}

PALAVRAS-CHAVE: Educação Profissional. Agente Comunitário de Saúde.

\section{Introdução}

A Estratégia Saúde da Família (ESF), conhecida nacionalmente como o Programa Saúde da Família (PSF), constitui-se atualmente na vitrine do sistema local de saúde. No cenário da política de saúde brasileira, este modelo de atenção em saúde, pautado no paradigma da vigilância à saúde, tem promovido mudanças estruturais, tanto quantitativas quanto qualitativas, no quadro da saúde coletiva no Brasil. Inicialmente considerado como um programa, o saúde da família foi alçado à condição de estratégia para reorientação da assistência, que passaria a ser guiada pelos princípios de uma política de atenção primária ou de atenção básica (CONILL, 2002).

\footnotetext{
${ }^{1}$ UFU - Universidade Federal de Uberlândia. Escola Técnica de Saúde. Uberlândia - MG - Brasil. 38411162 fasoane@estes.ufu.br

${ }^{2}$ UFU - Universidade Federal de Uberlândia. Escola Técnica de Saúde. Uberlândia - MG - Brasil. 38411162.
} 
A ESF propõe uma ampliação do lócus de intervenção em saúde, incorporando na sua prática o domicílio e espaços comunitários diversos e vem contribuindo para o fortalecimento do vínculo entre profissionais das equipes de saúde e comunidade. Para isso, conta-se com uma equipe multiprofissional composta por médico, enfermeira, auxiliar de enfermagem e uma nova categoria profissional, criada a partir das primeiras iniciativas de se implantar essa estratégia no Brasil, que é o Agente Comunitário de Saúde (ACS). Com a incorporação desse novo profissional na área da saúde coletiva, surgiram novas demandas para a educação profissional no setor saúde, a qual já tinha como perspectivas a inclusão social dos trabalhadores pela elevação da sua escolaridade e a melhoria da qualidade da assistência à população. Segundo Riani (apud ESP/MG, 2007, p.7):

O desafio que se impõe é o de formar o Agente Comunitário de Saúde, este importante profissional da estratégia de saúde da família, para atender as suas necessidades de inserção profissional no campo da saúde, rumo `as novas exigências das melhorias na prestação do serviço de saúde à comunidade.

O presente trabalho tem como objetivo discutir a formação inicial dos trabalhadores de saúde a partir do Módulo I do Curso Técnico de Agente Comunitário de Saúde oferecido pela Escola Técnica de Saúde da Universidade Federal de Uberlândia junto às Gerências Regionais de Saúde dos municípios de Uberlândia e Ituiutaba, em Minas Gerais. A etapa inicial do curso, perfazendo um total de 400 horas, trouxe muitos desafios, tanto para os profissionais da educação envolvidos quanto para os trabalhadores incluídos no processo, propiciando vários questionamentos, os quais este estudo tentou responder: Quais os reais desafios que a educação inicial do ACS traz para a educação profissional? Quais as conquistas possíveis para profissionais e para o setor saúde?

\section{O agente comunitário de saúde e a formação profissional}

As perspectivas delineadas para a Educação Profissional Brasileira no Setor de Saúde, com destaque para a inclusão social dos trabalhadores pela elevação de sua escolaridade, impõem políticas públicas educativas gerais e especificas. A própria reforma da Educação Profissional Brasileira pode ser considerada uma Política Pública Geral, com suas Leis, Pareceres, Decretos e Referenciais Curriculares, determinando e orientando o agir sob um paradigma pedagógico de transferência, na prática educacional, dos conteúdos para as 
competências, com propostas de itinerários formativos a fim de atender ao novo perfil de laborabilidade/trabalhabilidade (BRASIL, 2000). Neste contexto, as Diretrizes Curriculares Nacionais de Educação Profissional Técnica de Nível Médio para a Saúde determinam uma carga-horária mínima de 1.200 horas para os cursos técnicos (BRASIL, 2001).

Como Política Pública específica na área de Saúde, dentre outras, destaca-se o Projeto de Profissionalização dos Trabalhadores da Área de Enfermagem (PROFAE) que teve como objetivo assegurar aos usuários do SUS cuidados e assistência de enfermagem prestados por profissionais competentes e deu o direito a esses trabalhadores de complementarem o ensino fundamental e/ou acessarem a educação profissional (BRASIL, 2003).

Atualmente, novas políticas estão sendo implementadas em atenção ao novo profissional integrante da equipe de Saúde da ESF, o Agente Comunitário de Saúde. Desse modo, em 2002, temos a criação da profissão do ACS pela Lei nº 10.507 de 10/07/2002 (BRASIL, 2006a); em 2004 a publicação dos Referenciais Curriculares para o Curso Técnico de Agente Comunitário de Saúde descrevendo as funções, as sub-funções, as competências, as habilidades e as bases tecnológicas, para um curso modular de 1.200 horas com conteúdos teóricos e práticos e, em 2006, pela Portaria 648 de 28/03/2006 (BRASIL, 2006b), foram definidas as atribuições do ACS na Equipe de Saúde. A partir dessas ações, o Ministério da Saúde financiou a nível nacional o primeiro módulo do Curso Técnico de Agente Comunitário de Saúde, o qual foi implantado pelos estados.

No Estado de Minas Gerais, a implementação da formação desses profissionais ficou sob a responsabilidade das instituições públicas formadoras de recursos humanos da área da saúde em parceria com o Ministério da Saúde, por meio da Secretaria de Gestão do Trabalho e Educação na Saúde - SGTES e seu Departamento de Gestão da Educação na Saúde - DEGES. A Escola de Saúde Pública do Estado de Minas Gerais assumiu a formação do ACS no Estado buscando parcerias, dentre elas a Escola Técnica de Saúde da Universidade Federal de Uberlândia.

As ações propostas para o curso foram delineadas a partir da política de educação profissional, que considera a atuação do ACS junto às famílias e comunidade no papel de agente promotor da saúde. A proposta pedagógica se fundamentou em concepções filosóficas críticoreflexivas tendo como eixos norteadores o aprender a aprender, a autonomia, a integração teoriaprática e a articulação do processo ensino-aprendizagem e do trabalho. A estrutura do curso teve 
como princípios a articulação teoria-prática, ensino e serviço sustentada na interdisciplinaridade. Foi organizado em 03 módulos, cada um distribuído em unidades didáticas específicas. As atividades de ensino-aprendizagem foram realizadas em dois momentos denominados períodos de concentração e dispersão: os períodos de concentração foram constituídos por situações de reflexões sobre a prática e sistematização do conhecimento teórico; os períodos de dispersão caracterizados pela reorganização do processo de trabalho e realizados em serviço (ESP/MG, 2007).

\section{A formação inicial do agente comunitário de saúde na ESTES/UFU}

A Formação Inicial do ACS na ESTES/UFU se efetivou por meio do Projeto denominado Curso de Formação Inicial dos Agentes Comunitários de Saúde das GRS de Uberlândia e Ituiutaba. Teve como objetivos:

- capacitar o contingente de ACS dos municípios pertencentes as duas GRS como profissional de interface intersetorial da assistência social, educação e meio ambiente;

- a Capacitação Pedagógica de toda a equipe do projeto (professores, instrutoras, coordenadores locais, supervisores pedagógicos, coordenador técnico-pedagógico e coordenador geral) totalizando 200 educadores.

A matriz curricular adotada teve como base a proposta do Curso Técnico de ACS da Escola de Saúde Pública do Estado de Minas Gerais, Modulo I, com carga-horária de 400 horas, prevendo-se 200 horas para os períodos de concentração e 200 horas para os períodos de dispersão. A interação escola-serviço foi fator essencial e indispensável para que o processo formativo se efetivasse. Nessa perspectiva, o curso foi executado em 12 municípios sedes, contemplando 26 municípios em sua abrangência e totalizando 24 turmas. Para a organização das turmas, foi observado o princípio da descentralização e a proximidade geográfica dos municípios envolvidos a fim de permitir fácil acesso do aluno à formação. A relação professor/aluno foi de 1/30 a 1/40 na concentração e de 1/6 na dispersão. O Curso teve início em junho de 2007 com término em fevereiro de 2008. Dos 857 ACS integrantes das equipes da Saúde da Família e PACS de Uberlândia e Ituiutaba, 819 ACS concluíram o Curso com aprovação, atingindo, desta forma, 95,5\% da meta. 
A capacitação Pedagógica foi desenvolvida em quatro etapas com carga horária de 24 horas por etapa, totalizando 96 horas. A primeira etapa foi realizada em parceria com a ESP/MG tendo como objetivos a contextualização histórica das diferentes abordagens pedagógicas presentes nos processos educativos em geral e na saúde em particular; a reflexão sobre as ações pedagógicas mais utilizadas na área de saúde, a apresentação do instrumento Guia Curricular do Curso de Formação do Agente Comunitário de Saúde, as formas de integração dos conteúdos e práticas, a relação trabalho/ensino, teoria/prática, aluno/docente e a avaliação do processo. As demais etapas foram desenvolvidas de acordo com o cronograma dos períodos de concentração e dispersão das unidades nos próprios municípios sedes, tendo como objetivos o estudo e distribuição dos conteúdos inerentes a cada unidade, contextualizando a realidade com a utilização de estudos de casos, relatos de experiências, e revendo a prática docente com avaliação da ação educacional.

\section{Material e Método}

O presente trabalho teve como objetivo analisar os discursos sobre a Formação Inicial do ACS, produzidos durante o módulo I do Curso de Formação Inicial dos Agentes Comunitários de Saúde das GRS de Uberlândia e Ituiutaba optando-se por uma abordagem qualitativa, tendo como base o referencial da Análise do Discurso estabelecido por Bardin (1995).

A mostra constou de uma população de 857 alunos e 200 docentes. Foram analisados os discursos de 80 alunos e 20 docentes, escolhidos aleatoriamente, contemplando 11 dos 12 municípios integrantes do Projeto. Um município não participou da pesquisa. Como instrumento, utilizou-se um questionário semi-estruturado, aplicado a toda população com o devido Termo de Consentimento autorizado, contendo questões avaliativas referentes ao Curso de Formação Inicial do ACS. A coleta de dados foi obtida por meio dos relatos escritos oriundos das justificativas de seis questões do questionário escolhidas para este estudo. Com a finalidade de preservar o anonimato, os questionários foram identificados segundo numeração arábica sendo sujeitos de 1 a 80 os alunos e de 81 a 100 os docentes.

\section{Resultados e discussão}


A análise do discurso coletivo nos leva a uma visão macro do assunto proposto neste estudo. Por meio das falas dos sujeitos é possível uma análise dos desafios impostos para a educação profissional dos ACS como a proposta pedagógica de interação ensino-serviço, a heterogeneidade dos educandos, as dificuldades estruturais e funcionais devido ao grande número de atores envolvidos direta ou indiretamente no processo.

Seguem abaixo a análise das questões escolhidas, as quais foram categorizadas a partir da síntese das idéias principais dos sujeitos da pesquisa.

\section{Questão 1: Carga horária \\ Categoria: cansativa e suficiente}

Muitos sujeitos referiram-se à carga horária como cansativa, porém suficiente para as atividades propostas. A carga horária entendida como cansativa compreendeu as 8 (oito) horas de atividades diárias durante o período de Concentração. Para o período da Dispersão, onde as 40 horas de cada unidade foram cumpridas no horário de trabalho de 4 horas diárias, as opiniões foram de que eram suficientes para as atividades, com ressalvas sobre a questão da demanda normal do serviço dificultar as propostas didáticas do Curso. Nesse sentido, entende-se que o processo de aprendizagem ensino-serviço pode acarretar dificuldades tanto para o educando como para o educador, pois naqueles momentos dedicados ao aprendizado não foi possível dissociar o trabalhador de suas funções.

\footnotetext{
“Acho um pouco cansativo oito horas diárias, mas tudo bem. Vale a pena. É compatível com nosso horário de trabalho, suficiente para as atividades”. (sujeito 57)

“Devido à carga horária, o trabalho do ACS fica a desejar.” (Sujeito 83).

"Carga horária suficiente para trabalhar os conceitos e construir o conhecimento.” (Sujeito 81).
}

\section{Questão 2: Proposta Pedagógica/Currículo Integrado}

\section{Categorias: aprendizagem concreta e significativa: oportuniza o pensar e expor as idéias e conteúdos repetitivos}


O discurso do sujeito coletivo em relação à proposta pedagógica ratifica os pressupostos da metodologia do Curso. Tanto alunos quanto docentes referem-se a esta proposta como propícia à construção do conhecimento por estar baseada na experiência do aluno; por oportunizar o pensar e à exposição de diferentes idéias. Por outro lado, muitos sujeitos relatam que algumas atividades e conteúdos se tornam repetitivos. Este aspecto pode ser compreendido considerando que esta metodologia propõe atividades que conduzam ao repensar da prática e do conhecimento adquirindo por meio dos diferentes procedimentos de ensino (exposição dialogada, trabalho em grupo, estudo de caso, dramatizações e dinâmicas).

A possibilidade de realizar uma capacitação no horário de trabalho, proposta interação ensino-serviço, é referida como ideal, gratificante.

\footnotetext{
“É bom porque é horário de trabalho.” (Sujeito 57).

"Tudo o que é aprendido na concentração é passado nas visitas.” (Sujeito 39).

"Só não sei se é bom porque tem alguns assuntos que se repetem." (Sujeito 28).

"As experiências vividas por outras equipes e conhecimentos reais são trazidos." (Sujeito 25).

"Proposta construtiva do conhecimento, muito importante, pois é baseado em experiência do aluno.” (Sujeito 82).

"Da oportunidade de todos pensarem e exporem suas idéias."

(Sujeito 90).
}

\section{Questão 3: Apropriação do Conteúdo}

\section{Categoria: Saber, Saber Fazer}

A percepção da apropriação do conteúdo, no discurso dos alunos, foi evidenciada como uma aprendizagem constituída por meio do agir consciente, pela aplicabilidade do conhecimento aprendido nas atividades desenvolvidas no Trabalho, pelo fazer e no saber por quê fazer.

"Já estou realizando meu trabalho com os conhecimentos adquiridos.” (Sujeito 4)

"Eu precisava ter mais clareza do que faço" (Sujeito 55).

"Me torna a cada mês uma profissional mais capacitada e cheia de empolgação a expor mais conhecimentos" (Sujeito 37).

"Está me ajudando a realizar trabalho melhor" (Sujeito 3).

"A cada dia que passa com o curso adquirimos mais conhecimentos e equilíbrio para manuseio da tarefa” (Sujeito 20). 
A contribuição dos docentes a esta questão constitui-se de apenas três relatos, sendo que dois apontaram a aprendizagem significativa como um fator ideal para a apropriação do conhecimento. Porém, um depoimento destaca a questão da escolaridade como um fator dificultador para o processo ensino-aprendizagem.

"Muito bom porque está relacionado com o serviço que os mesmos realizam, com mais fundamentos teóricos.” (Sujeito 87).

"Existem alguns ACS com grandes limitações principalmente por não possuir o $2^{\circ}$ grau completo.” (Sujeito 91).

Em síntese, percebe-se que o foco do trabalho educacional de ensinar foi deslocado para o aprender, para a contribuição de competências, pelo aluno, articulados com conhecimentos teóricos/práticos, habilidades, permitindo uma aprendizagem significativa evidenciada pelo desempenho competente dos seus fazeres profissionais o que reforça a proposta da educação profissional:

A realização competente tem nela agregados saberes cognitivos, psicomotores e socioafetivos. A competência caracteriza-se pela condição de alocar esses saberes como recursos por meio de análises, sínteses, generalizações, analogias, associações, transferências [...]”. (BRASIL, 2000, p.10).

\section{Questões 4,5 e 6:}

\section{4: Interesse pelo Curso}

\section{5: Atendimento de Expectativas}

\section{6: Contribuição do Conhecimento Adquirido para a Melhoria do Processo de Trabalho}

Os discursos apresentados nas questões 4, 5 e 6, foram, em sua maioria, os mesmos, permitindo-se desta forma o agrupamento delas para análise.

\section{Categoria: Ser Profissional}

Observa-se pelos discursos dos alunos que o curso possibilitou uma compreensão quanto ao valor do próprio trabalho e do trabalho do outro em relação a ele e à comunidade em que 
atuam; da importância da aprendizagem, da qualificação para o desempenho de suas funções, para ser um profissional.

“Está me ajudando a ser um bom profissional” (Sujeito 49).

"Através dele descubro o que é realmente ser ACS.” (Sujeito 17).

"Várias contribuições entre elas a valorização do ACS.” (Sujeito 34).

"Através do conhecimento absorvido, hoje tenho mais estratégia para levar promoção e prevenção para minha comunidade.” (Sujeito 23).

"Visão ampla da área do trabalho." (Sujeito 1).

Com relação aos docentes, somente foi computada a questão 6, considerando-se que as questões 4 e 5 só foram aplicadas aos alunos. O discurso dos docentes também contempla o SER profissional.

\footnotetext{
"Buscar melhorar a qualidade do trabalho realizado.” (Sujeito 87).

"A qualidade das visitas, a integração das equipes melhorou significativamente.” (Sujeito 89).

"Após a discussão dos conteúdos, os próprios alunos detectam as falhas da equipe ou do sistema de saúde.” (Sujeito 85).
}

\section{Considerações finais}

A partir da análise dos discursos, observa-se que a formação inicial dos ACS das GRS de Uberlândia e Ituiutaba reforça os pressupostos de Educação Profissional, que tem como paradigma o foco nas competências a serem desenvolvidas e nos saberes (saber, saber fazer e saber ser). A utilização da Proposta Pedagógica do currículo integrado, contextualizado com a realidade do aluno, com a sua vivência para a ressignificação de seu cotidiano e para a qualificação e habilitação profissional por si só representa um enorme desafio em todos os níveis de formação que contemplam em sua grade curricular a prática. Na área da saúde, tal fato é evidenciado nos estudos avaliativos e no cotidiano dos educadores. Os resultados obtidos apontam para conquistas tanto nas questões pessoais quanto na melhoria da qualidade do serviço prestado ao usuário. A experiência obtida no primeiro módulo do curso técnico de agentes comunitários de saúde evidencia a sua aplicabilidade nos módulos subseqüentes bem como na educação profissional.

Por outro lado, a partir da Inclusão no Catálogo Nacional de Cursos Técnicos, Eixo Tecnológico Ambiente, Saúde e Segurança, do Curso Técnico em ACS no MEC, o estudo aponta 
para outros desafios no sentido de Implementação da Política de Formação do ACS com a continuidade dos módulos subseqüentes para a habilitação desses profissionais como Técnicos em ACS.

Concluindo, a própria visão dos profissionais em relação à sua formação e à contribuição para o setor saúde aponta para questões como aprimoramento do trabalho, valorização profissional, intercâmbio de experiências e objetividade no atendimento da comunidade.

\section{INITIAL FORMATION OF WORKERS: POLITICS, CHALLENGES AND CONQUESTS IN THE PROFESSIONAL EDUCATION}

ABSTRACT: This study has as objective discusses the initial formation near the proposal of Competence of the Communitarian Agent of Health (CAH) The question is an inquiry of qualitative nature, with random collection of the discursive data of 100 professionals, who constitute the empirical base of the inquiry, from January to May of 2008. The perspectives outlined for the Professional Brazilian Education in the sector health, with distinction for the social inclusion of the workers for the elevation of his schooling, impose public educative specific politics. The proposal for the first entrance in the professional word of the people of middle level in acting in the sector of the health belongs to a politics of formation from formative itineraries. In 2004, the referential system curricular for the Technical Course of CAH proposes a modular course with workload of 1200 hours, with theoretical and practical content. In 2007, the Technical School of Health of the UFU, in partnership with the School of Public Health of MG and GRS of Uberlândia and Ituiutaba, Minas Gerais, Brazil, develops the Module I of the Course of initial formation, workload of 400 hours, with 857 pupils and 200 teachers. This study has as objective discusses the initial formation near the proposal of Competence of the TCC. The question is an inquiry of qualitative nature, with random collection of the discursive data of 100 professionals, who constitute the empirical base of the inquiry, from January to May of 2008. The conclusion is that there's a satisfactory improvement in the services rendered for the best enabled professional and for the necessity of a spacious discussion about the continuity of the public politics for the Professional Education.

KEYWORDS: Professional education. Communitarian Agent of Health.

\section{REFERÊNCIAS}

BARDIN, L. Análise de conteúdo. Tradução de Luis Antero Reto e Augusto Pinheiro. Lisboa: Edições 70,1995.

BRASIL. Senado Federal. Lei n ${ }^{\circ} .10 .507$ de 10 de julho de 2002. Cria a Profissão de Agente Comunitário de Saúde e dá outras providências. Diário Oficial da União, Brasília, 10 jul.2002. Disponível em: <http://saúde.gov.br>. Acesso em: 12 ago. 2006a. 
. Ministério da Saúde. Portaria $n^{\circ} .648$ de 28 de março de 2006. Aprova a Política Nacional de Atenção Básica, estabelecendo a revisão de diretrizes e normas para a organização da Atenção Básica para o Programa Saúde da Família (PSF) e o Programa Agentes Comunitários de Saúde (PACS). Diário Oficial da União, Brasília, 28 mar. 2006. Disponível em: $<$ http://saúde.gov.br>. Acesso em: 12 ago. 2006b.

. Ministério da Saúde. Referencial curricular para o curso técnico de agente

comunitário de saúde. Brasília: Ministério da Saúde, 2004.

. Ministério da Saúde. Avaliação do impacto do PROFAE na qualidade dos serviços de saúde. Formação, Brasília v.3, n.7, p.89-112, jan/abr. 2003.

Ministério da Educação. Educação profissional: legislação básica. Brasília: MEC, 2001.

.Ministério da Educação. Educação Profissional: referenciais curriculares nacionais da educação profissional de nível técnico-área profissional: saúde. Brasília: MEC, 2000.

CONILL, E. M. Políticas de atenção primária e reformas sanitárias: discutindo a avaliação a partir da análise do Programa Saúde da Família em Florianópolis, Santa Catarina, Brasil, 19942000. Cadernos de Saúde Pública, Rio de Janeiro, v.18, p.191-202, 2002.

ESCOLA DE SAÚDE PÚBLICA [ESP/MG]. Curso técnico de agente comunitário de saúde: Módulo I: Formação Inicial do Agente Comunitário de Saúde. Belo Horizonte: ESP/MG, 2007. 